\title{
HOSPITAL DIARRHOEA
}

\author{
BY
}

\author{
PHILIP EVANS, M.D., M.Sc., M.R.C.P.
}

(From Cuckfield Emergency Hospital)

Institutional diseases, such as jail fever, hospital gangrene, and child-bed fever, have declined in importance. The same may be said of hospital diarrhoea, but it still affects thousands of children and kills hundreds of infants. The problem of its control has been reaccentuated by the use of emergency hospitals for children, and by the difficulty of getting for them nurses who are entirely adequate in numbers and training.

The problem is not clear-cut, for conditions vary widely, but a short account of the occurrence of diarrhoea, not due to purgation or obvious dietary indiscretions, in the children admitted to one such hospital may be interesting. An attempt has been made to classify the attacks epidemiologically, as this method is the most likely to help the planning of preventive measures.

The hospital has had a varying number of beds for adults and children, and the occupancy has fluctuated, particularly with season and with changes in policy. But generally there have been 110-130 beds for children, arranged in five nursing units, with five open wards of $18-25$ beds. One unit also has an eight-bed and two two-bed wards; another has four sick-rooms for nurses in addition to a large ward for children.

Between Nov. 1, 1939 and Jan. 31, 1942 nearly two thousand children were admitted, and nearly a quarter of them were infants under two years old. There were 203 attacks of diarrhoea, starting after admission to hospital, and infants were affected over twice as often (proportionately) as older children (table 1). In addition, ten nurses had Sonne dysentery.

TABLE 1

ADMISSIONS AND ATTACKS OF DIARRHOEA FROM $1 / 11 / 39$ TO $31 / 42$

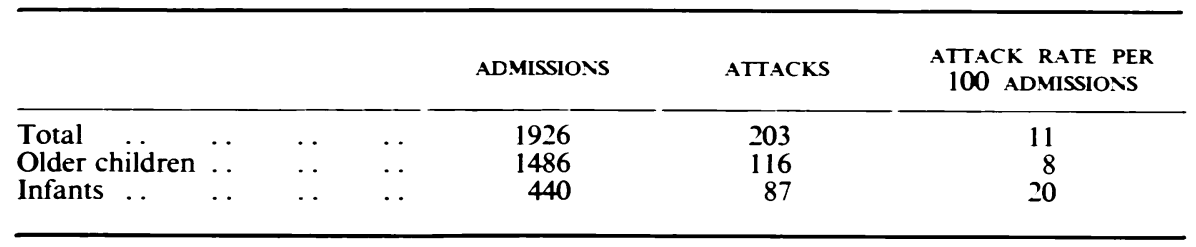

There was no striking seasonal incidence, though the summer months were fairly trouble-free. 
The attacks were divided into epidemic (190) and sporadic (13). The epidemics were divided into ' food poisoning,' bacillary dysentery, and other outbreaks (fig. 1). From fig. 2 it may be seen that the infants had no special liability to food poisoning or dysentery, but that the other outbreaks and the sporadic cases were almost confined to infants less than two years old.

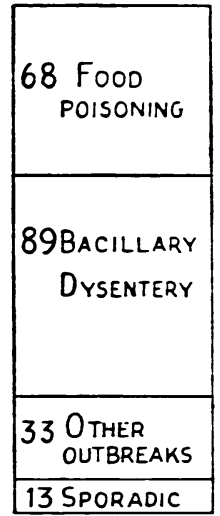

FIG. 1.-Types of diarrhoea developed by children in hospital.

\section{Food poisoning}

Outbreaks were thought to be due to 'food poisoning' when a number of patients were afflicted with diarrhoea almost simultaneously. The illness was acute and transitory, being over in a few hours; it was sometimes distressing, but did not produce severe illness; vomiting was rare, pyrexia absent; some children complained of abdominal pain; mucus, blood, and pus were not seen in the stools, and no pathogenic organisms were grown from them. Adults as well as children were affected.

Two outbreaks, affecting 49 of the hospital children, were traced to the consumption of minced meat, although meat cut from the same joints, but not minced, was innocuous. The mincing machine was looked after by a mentally defective kitchen worker and, although it was supposed to have been thoroughly cleaned, it was found on one occasion to contain a large crumb of minced meat from the previous day's supply. Chemical changes could be produced in such a pabulum by the activity of ordinarily non-pathogenic organisms (see Topley and Wilson, 1936), and the toxins would be mixed with part of the next day's mince. This was put in an oven to keep warm for half an hour before being sent to the wards, and further changes might take place during this incubation.

\section{Bacillary dysentery}

This group consists of patients who acquired dysentery, shown bacteriologically to be due to Sonne bacilli, in hospital, and also those patients who developed diarrhoea, with negative stool cultures, in the same wards at the same time as the proved cases. This may have caused the inclusion of a few 
non-dysenteric patients, but from analysis of the symptoms in the stool-positive and -negative groups I do not think any large error has been introduced.

The outbreaks varied in size; in all there were five outbreaks affecting 10 nurses and 89 children. Infection was often brought into the hospital by children who were admitted with the disease, but the largest epidemic followed a primary case in a nurse, who may have been infected in her billet. The condition spread from individual to individual, and not by food-contamination. On two occasions the epidemic got really out of hand, spread to other wards, and affected over $\mathbf{4 0}$ people before coming under control.

Why should it be so difficult to prevent an obviously preventable disease? Several reasons spring to the mind:

1. The diagnosis may not be made early enough; e.g. a boy was admitted with abdominal pain and tenderness, pyrexia and vomiting. His appendix was removed and he was back in the ward just in time to start having diarrhoea, blood and mucus being seen in the stools the next day. Again, a patient was transferred from one ward to another; she had slight frequency and looseness of the stools, but no particular attention was paid to them; a week later a patient in the second ward developed frank dysentery; Sonne bacilli were then found in the faeces of the first patient.

2. The disease is mild, and may be undetected, particularly in nurses. One child who was said to have had only one loose stool excreted dysentery bacilli for a month. Both convalescent and healthy temporary carriers may be encountered.

3. Children with dysentery often become incontinent and pollute the bed clothes instead of defaecating tidily into a chamber. If several children have dysentery at the same time the strain on the nursing staff is considerable.

4. In England dysentery is usually mild, and precautions against its spread are often not carried out as rigorously as in typhoid fever, for example. Yet it is known that the Sonne bacillus can kill infants (see, for instance, the account of Nabarro and Signy, 1932).

5. Many bacteriologists have been slow to use improved methods of detecting the organisms, and many paediatricians slow to insist on the bacteriological evidence of freedom from infection which they would require in typhoid fever. Table 2 shows that a minority of patients excrete Sonne bacilli for some weeks, although the diarrhoea only lasts for a few days, and also that one negative stool culture does not preclude the possibility of continued infection.

TABLE 2

\section{STOOL CULTURES IN PATIENTS WITH SONNE DYSENTERY}

90 had stools cultured twice or more

57 had positive cultures

54 were positive in the 1st week

$26, ", "$, "nd ",

$4, \quad, \quad, \quad$ 3rd ",

1 " " " $"$ 4th ",

10 hä a positive culture after one negative

3 had a positive culture after two negative 
In this hospital the infection was introduced into an uncontaminated ward eighteen times, and secondary cases followed on nine occasions. In four of these there was evidently a failure in the technique of isolation of a known patient; in two the diagnosis was not made promptly enough; in one a nurse was allowed to go back on duty only a week after ceasing to have diarrhoea, and when only one negative stool culture had been obtained; in two no source of infection was discovered, and undiagnosed infection in the nurses seemed likely.

\section{Other outbreaks}

The other outbreaks of diarrhoea were small and almost restricted to infants (fig. 2), who were in many instances underweight, though some were

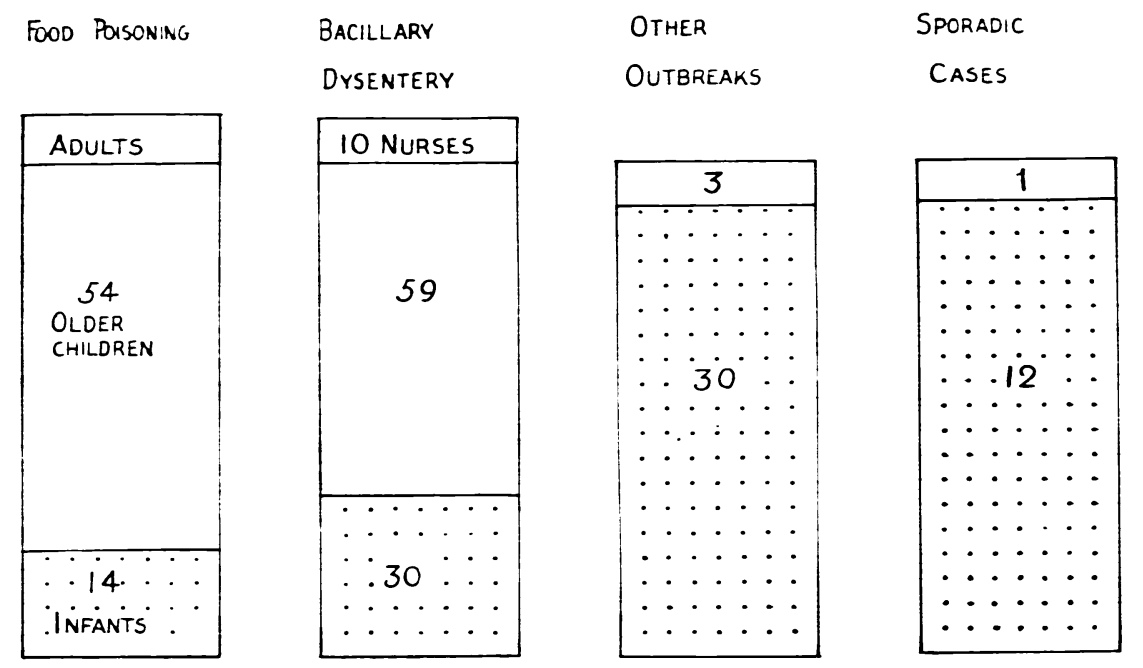

FIG. 2.-Diarrhoea in relation to age.

excellently nourished. The illness was usually mild, consisting of diarrhoea, often with the passage of mucus but no blood or pus; at times the illness was severe, with vomiting, dehydration and pyrexia-in short, ${ }^{\circ} \mathrm{D}$. and $\mathrm{V}$. $^{\cdot}$ No pathogenic organisms were discovered in the stools, and the food was not to blame, for infants on different varieties of milk were affected alike.

In the seventh outbreak, two of the affected infants had acute otitis media, and other evidence of respiratory infection was sought. It was found, when looked for, in each outbreak (table 3, no. 6 to 10). Although the infants with diarrhoea often had no sign of acute respiratory illness, the older children were usually suffering simultaneously in a ward epidemic of influenza, sore throat, or common cold (see fig. 3). The importance of parenteral, especially respiratory, infection in causing 'gastroenteritis' is well known, but it would appear that the signs of respiratory infection must sometimes be sought in the older children rather than in the infants with diarrhoea. 
TABLE 3

OTHER OUTBREAKS OF DIARRHOEA

\begin{tabular}{|c|c|c|c|c|c|}
\hline \multirow{2}{*}{$\begin{array}{l}\text { OUT- } \\
\text { BREAK }\end{array}$} & \multirow{2}{*}{ DATE } & \multicolumn{2}{|c|}{ NO. AFFECTED } & \multicolumn{2}{|c|}{ RESPIRATORY DISEASES IN: } \\
\hline & & INFANTS & $\begin{array}{l}\text { OLDER } \\
\text { CHILDREN }\end{array}$ & $\begin{array}{l}\text { CHILDREN WITH } \\
\text { DIARRHOEA }\end{array}$ & OTHER CHILDREN \\
\hline $\begin{array}{r}1 \\
2 \\
3 \\
4 \\
5 \\
6 \\
7 \\
8 \\
9 \\
10\end{array}$ & $\begin{array}{l}1938 \text { Dec. } \\
1939 \text { Dec. } \\
1939 \text { Dec. } \\
1939 \text { Dec. } \\
1940 \text { Jan. } \\
1940 \text { Mar. } \\
1940 \text { Apr. } \\
1940 \text { Oct. } \\
1940 \text { Nov. } \\
1941 \text { Feb. }\end{array}$ & $\begin{array}{l}5 \\
2 \\
7 \\
2 \\
0 \\
2 \\
4 \\
2 \\
2 \\
4\end{array}$ & $\begin{array}{l}0 \\
0 \\
0 \\
0 \\
2 \\
0 \\
0 \\
0 \\
0 \\
1\end{array}$ & $\begin{array}{l}\frac{-}{-} \\
\frac{-}{0} \\
2 \text { had otitis } \\
\text { Both had bronchitis } \\
0 \\
1 \text { rhinitis } \\
1 \text { pharyngitis }\end{array}$ & $\begin{array}{c}? \\
? \\
? \\
? \\
10 \text { had influenza } \\
? \\
\text { 4 had respiratory infection } \\
5 \text { had respiratory infection, } \\
2 \text { had unexplained pyrexia }\end{array}$ \\
\hline
\end{tabular}
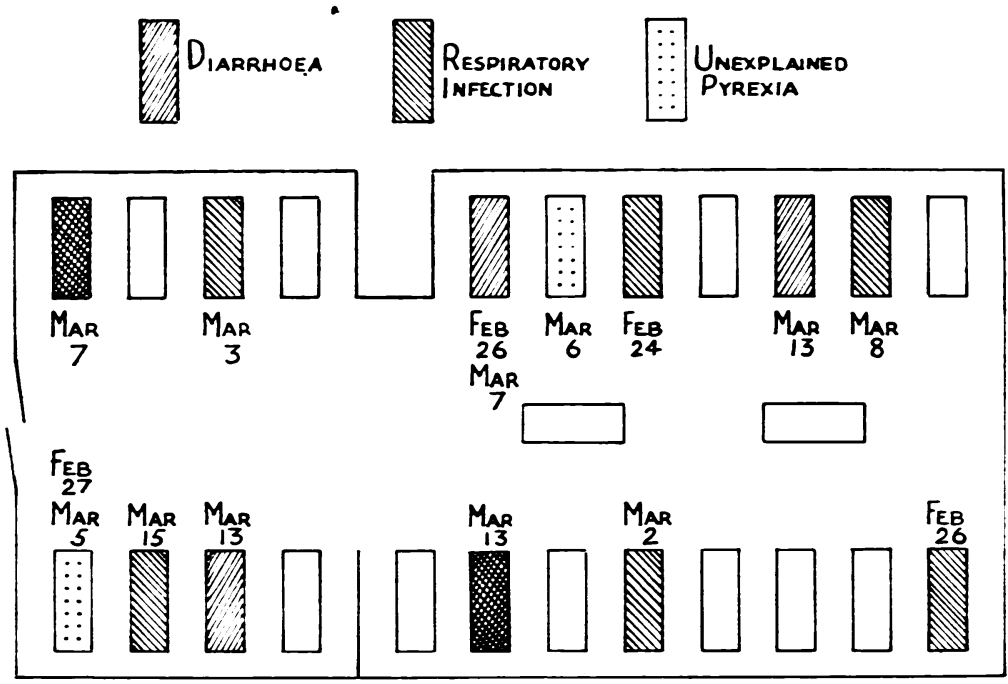

FIG. 3.-Plan of ward showing incidence of respiratory infection and diarrhoea, Feb.-March, 1941.

\section{Sporadic cases}

The smallest group consists of the children who developed non-epidemic diarrhoea, but it is important. There were six children over a year old in this group, and all survived, but of the seven under a year old, six died.

The illness was, therefore, often severe; it was often associated with vomiting and pyrexia; blood and pus were absent from the stools, which contained no pathogenic organisms; dehydration was apparent in the severe cases. This was, then, also typical ' D. and V.'

From table 4, certain features may be seen to be common to these patients: they were young, and a parenteral infection was often present. Only one was 
not underweight before the development of diarrhoea, and he (case 4) had infantile eczema, which notoriously predisposes to digestive disturbance.

TABLE 4

SPORADIC CASES OF DIARRHOEA

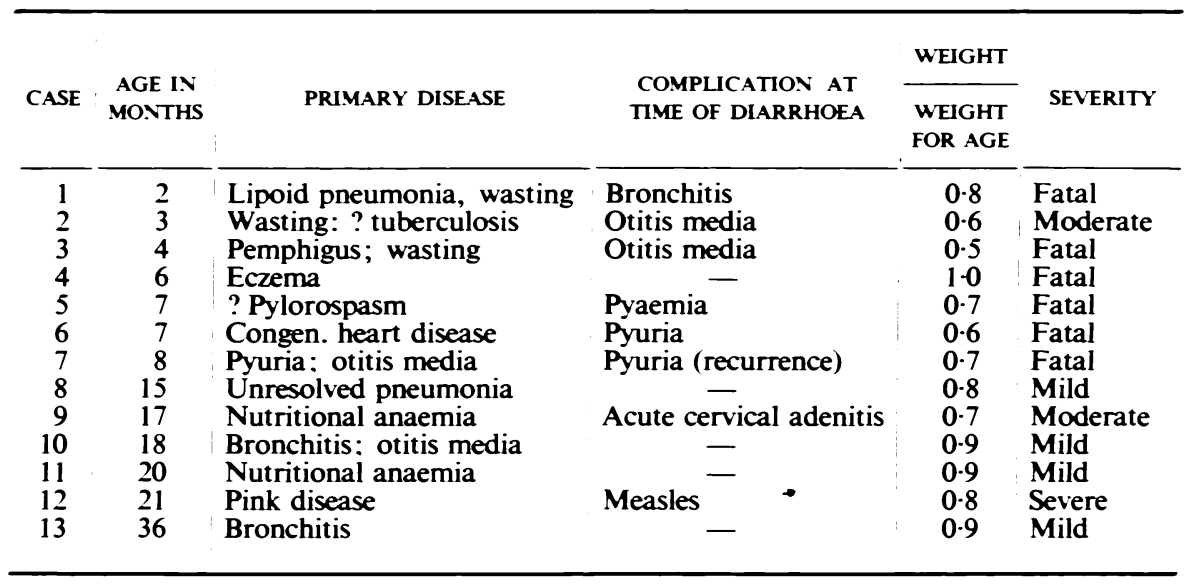

\section{Prophylaxis}

This survey has not shown the existence of any mysterious ailment of unknown origin. There are mysterious outbreaks-for example, neonatal diarrhoea-but enough is known to make possible the prevention of many attacks. This is not the place for a detailed programme of prophylaxis, for that must be worked out independently for each hospital. Measures must not, however, be taken against only one type of 'gastroenteritis'; many points must be considered: for example, sterilization of feeds and feeding-bottles, disposal of excreta, improved bacteriological methods in bacillary dysentery, the health of the nurses, alertness and awareness of nurses and doctors, isolation, air sterilization, masks, and the prompt diagnosis of urinary infections in infants.

\section{Summary}

Epidemics of diarrhoea are all too common in children's hospitals, and epidemiological classification can point the way to prophylaxis. In one hospital the outbreaks could be divided into attacks of 'food poisoning,' of Sonne dysentery (which is difficult to control for a variety of reasons), and of diarrhoea affecting infants but probably due to infections which cause respiratory infection in older children. In addition there were sporadic attacks affecting malnourished infants, who often had parenteral infection. Many of these sporadic attacks ended fatally.

\section{REFERENCES}

Nabarro, D., and Signy, A. G. (1932). Arch. Dis. Childh., London, 7, 327.

Topley, W. W. C., and Wilson, G. S. (1936). The principles of bacteriology and immunity, 2nd edition, London, 1255. 